\title{
Ursolic acid inhibits the invasive phenotype of SNU-484 human gastric cancer cells
}

\author{
EUN-SOOK KIM and AREE MOON \\ College of Pharmacy, Innovative Drug Center, Duksung Women's University, Seoul 132-714, Republic of Korea
}

Received September 4, 2014; Accepted November 12, 2014

DOI: $10.3892 / 01.2014 .2735$

\begin{abstract}
Metastasis is a major cause of cancer-related mortality in patients with gastric cancer. Ursolic acid, a pentacyclic triterpenoid compound derived from medicinal herbs, has been demonstrated to exert anticancer effects in various cancer cell systems. However, to the best of our knowledge, the inhibitory effect of ursolic acid on the invasive phenotype of gastric cancer cells has yet to be reported. Therefore, the aim of the present study was to investigate the effect of ursolic acid on the invasiveness of SNU-484 human gastric cancer cells. Ursolic acid efficiently induced apoptosis, possibly via the downregulation of B-cell lymphoma 2 (Bcl-2), the upregulation of $\mathrm{Bcl}-2$-associated $\mathrm{X}$ protein and the proteolytic activation of caspase-3. Furthermore, the activation of p38 mitogen-activated protein kinase and c-Jun N-terminal kinase was increased by the administration of ursolic acid. In addition, ursolic acid significantly suppressed the invasive phenotype of the SNU-484 cells and significantly decreased the expression of matrix metalloproteinase (MMP)-2, indicating that MMP-2 may be responsible for the anti-invasive activity of ursolic acid. Taken together, the results of the present study demonstrate that ursolic acid induces apoptosis and inhibits the invasive phenotype of gastric cancer cells; therefore, ursolic acid may have a potential application as a chemopreventive agent to prevent the metastasis of gastric cancer or to alleviate the process of metastasis.
\end{abstract}

\section{Introduction}

Gastric cancer is the second leading cause of cancer-related mortality worldwide (1) and the predominant cause of cancer-related mortality in numerous Asian countries, including South Korea and China (2). Gastric cancer is a multifactorial disease involving genetic and environmental factors (3). Furthermore, the prognosis of advanced gastric

Correspondence to: Dr Aree Moon, College of Pharmacy, Innovative Drug Center, Duksung Women's University, 419 Ssangmun-dong, Dobong-gu, Seoul 132-714, Republic of Korea E-mail: armoon@duksung.ac.kr

Key words: ursolic acid, cell invasion, matrix metalloproteinase cancer patients remains poor due to the high rate of metastatic recurrence $(4,5)$.

Ursolic acid is a pentacyclic triterpenoid compound that is derived from a range of medicinal herbs, including Rosemarinus officinalis, Eribotrya japonica, Calluna vulgaris and Oldenlandia diffusa (6-8). Ursolic acid has been demonstrated to exert a number of anticancer activities, including the inhibition of tumorigenesis, tumor promotion and angiogenesis (7), as well as the induction of apoptosis in various cancer cell lines, including melanoma, breast, gastric and hepatocellular carcinoma, human non-small cell lung cancer and liver cancer cell lines (7-12). In addition, ursolic acid has been reported to inhibit in vivo tumor growth in various animal models (13-15), and to suppress invasion and migration in human lung, breast and ovarian cancer cells $(10,16,17)$. However, to the best of our knowledge, the anti-invasive activity of ursolic acid in gastric cancer cells has yet to be reported. Therefore, the present study aimed to investigate the inhibitory effect of ursolic acid on the growth and invasive phenotype of SNU-484 human gastric cancer cells.

The process of tumor metastasis occurs by tumor cells disseminating from the primary tumor to distant secondary organs or tissues. Metastasis involves multiple steps, including the invasion, migration and dissemination of malignant tumor cells (18).Furthermore, cancer cell invasion has been extensively associated with the increased expression of matrix-degrading matrix metalloproteinase (MMP) enzymes $(19,20)$.

Apoptosis involves a series of cellular events that results in the activation of apoptosis-associated gene products, such as $\mathrm{B}$-cell lymphoma 2 (Bcl-2), Bcl-2-associated $\mathrm{X}$ protein (Bax) and the caspases $(21,22)$. The Bcl-2 and Bax proteins are functionally opposed: Whereas Bcl-2 acts to inhibit apoptosis, Bax promotes apoptosis $(23,24)$. Caspase- 3 is an apoptosis-associated cysteine peptidase that interacts with caspase- 8 and -9 , and is key in mammalian cell apoptosis (25).

In addition, a number of other molecules are involved in the process of apoptosis. The mitogen-activated protein kinase (MAPK) signaling pathways modulate gene expression, proliferation, motility and apoptosis (26-29). Activation of c-Jun N-terminal kinase (JNK) and p38 MAPK have been demonstrated to trigger apoptosis $(27,30,31)$, and extracellular signal-regulated kinase (ERK) activity promotes apoptotic pathways via the induction of mitochondrial cytochrome $c$ release, caspase- 8 activation or permanent cell cycle arrest (32). 
In order to examine the chemopreventive potential of ursolic acid in gastric cancer cells in vitro, the present study evaluated the effects of ursolic acid on proliferation, apoptosis and the invasive phenotype of SNU-484 human gastric cancer cells.

\section{Materials and methods}

Reagents. Ursolic acid (3 $\beta$-hydroxy-urs-12-en-28-oic acid), dimethyl sulfoxide (DMSO) and MTT were purchased from Sigma-Aldrich (St. Louis, MO, USA). Dulbecco's modified Eagle's medium (DMEM) was purchased from Cellgro Mediatech (Manassas, VA, USA), and fetal bovine serum and penicillin-streptomycin were purchased from Invitrogen Life Technologies (Grand Island, NY, USA). The annexin V-fluorescein isothiocyanate (FITC) apoptosis detection kit I was purchased from BD Biosciences (San Diego, CA, USA).

Cell lines. The SNU-484 gastric cancer cell line was provided by Dr H.D. Um (Korean Institute of Radiological and Medical Science, Seoul, South Korea). The SNU-484 cells were cultured in DMEM supplemented with $10 \%$ heat-inactivated fetal bovine serum and $100 \mathrm{U} / \mathrm{ml}$ penicillin-streptomycin. The cells were maintained in a humidified atmosphere of $95 \%$ air and $5 \% \mathrm{CO}_{2}$ at $37^{\circ} \mathrm{C}$.

MTT assay. SNU-484 cells cultured in a 96-well plate were treated with various concentrations of ursolic acid $(0,1,5,10$ and $25 \mu \mathrm{M}$ ) for $24 \mathrm{~h}$. Control cells were treated with DMSO equal to the highest percentage of solvent used under experimental conditions. Briefly, $25 \mathrm{mg} / \mathrm{ml} 0.5 \%$ MTT was added to the media and the cells were incubated for an additional $4 \mathrm{~h}$. Following removal of $100 \mu \mathrm{l}$ supernatant, which was replaced with an equal volume of DMSO, the absorbance was measured at a wavelength of $540 \mathrm{~nm}$ using an enzyme-linked immunosorbent assay (ELISA) plate reader (ELx800 ${ }^{\mathrm{TM}}$; BioTek Instruments, Inc., Winooski, VT, USA). The percentage of surviving cells was defined as the relative absorbance of treated versus untreated cells.

Flow cytometry analysis. The cells were grown in six-well plates and incubated for $24 \mathrm{~h}$ prior to treatment with ursolic acid. After $24 \mathrm{~h}$, the cells were harvested and washed twice with phosphate-buffered saline (PBS). The cells $\left(5 \times 10^{5}\right)$ were subsequently double-stained with FITC-conjugated annexin $\mathrm{V}$ and propidium iodide for $15 \mathrm{~min}$ at room temperature in $1 \mathrm{X}$ binding buffer, followed by analysis using a Vision CBA Image Cytometry system (Nexcelom Bioscience LLC, Lawrence, MA, USA).

Immunoblot analysis. The cells were cultured to $70 \%$ confluency and incubated in serum-free media containing various concentrations of ursolic acid $(0.0,1.0,2.5$ and $5.0 \mu \mathrm{M})$ for $24 \mathrm{~h}$. To prepare whole-cell extracts, the cells were washed with PBS and lysed by adding SDS-lysis buffer containing protease inhibitor cocktail (Roche Diagnostics $\mathrm{GmbH}$, Mannheim, Germany). Equal amounts of protein were subjected to $12 \%$ SDS-PAGE analysis and electrophoretically transferred to a polyvinylidene fluoride membrane (Bio-Rad
Laboratories, Hercules, CA, USA). Subsequently, the membranes were blocked with $5 \%$ w/v skimmed dried milk in PBS with Tween-20 (PBST) and incubated with primary (dilution, 1:1,000 in PBST) and secondary (dilution, 1:4,000 in PBST) antibodies, and detected using an enhanced chemiluminescence western blotting detection system (GE Healthcare Life Sciences, Chalfont, UK). Rabbit polyclonal anti-human p38 MAPK, rabbit polyclonal anti-human phosphorylated (phospho) p38 MAPK, rabit polyclonal anti-human phospho ERK1/2, mouse monoclonal anti-human ERK1/2, rabbit polyclonal anti-human JNK, mouse monoclonal anti-human phospho JNK and rabbit polyclonal anti-human poly(ADP-ribose) polymerase (PARP) antibodies were purchased from Cell Signaling Technology, Inc. (Beverly, MA, USA). Mouse monoclonal anti-human Bcl-2, mouse monoclonal anti-human caspase-3 and rabbit polyclonal anti-human Bax antibodies were purchased from Santa Cruz Biotechnology, Inc. (Santa Cruz, CA, USA).

In vitro invasion assays. An in vitro invasion assay was performed using a 24-well Transwell ${ }^{\circledR}$ unit with polycarbonate filters (Corning Costar, Inc., Cambridge, MA, USA). The lower side of the filter was coated with type I collagen, the upper side was coated with Matrigel (Collaborative Research, Lexington, KY, USA), the upper compartment of the Transwell ${ }^{\circledR}$ unit was filled with serum-free medium and the lower compartment was filled with the culture medium. Ursolic acid $(0.0,1.0,2.5$ and $5.0 \mu \mathrm{M}$ ) was also added to each compartment. The cells were placed on the upper side of the Transwell ${ }^{\circledR}$ plate and incubated for $24 \mathrm{~h}$. The cells that remained on the upper surface of the filter were removed with a cotton swab, while the cells that had migrated through the filter to the lower compartment were fixed with methanol and stained with crystal violet for $20 \mathrm{~min}$. The crystal violet dye retained on the filters was extracted using 30\% acetic acid and cell invasion was measured by reading the absorbance at $595 \mathrm{~nm}$ using an ELISA plate reader (ELx800; Bio-Tek Instruments).

Gelatin zymography assay. The cells were cultured to $70 \%$ confluency and incubated in serum-free media containing various concentrations of ursolic acid $(0.0,1.0,2.5$ and $5.0 \mu \mathrm{M})$ for $48 \mathrm{~h}$. The conditioned medium was collected and centrifuged at $13,000 \times \mathrm{g}$ for $10 \mathrm{~min}$ to remove cell debris. Subsequently, the protein concentration was measured using bicinchoninic acid assay reagents (Pierce Biotechnology, Inc., Rockford, IL, USA), and equal amounts of protein from the conditioned media were electrophoresed on $10 \%$ SDS-PAGE gels containing $1 \mathrm{mg} / \mathrm{ml}$ gelatin. Following electrophoresis, the gels were washed with renaturation buffer (2.5\% Triton X-100) three times for $30 \mathrm{~min}$, rinsed for $15 \mathrm{~min}$ with developing buffer $[50 \mathrm{mM}$ Tris- $\mathrm{HCl}$ buffer $(\mathrm{pH} 7.6)$ containing $5 \mathrm{mM} \mathrm{CaCl}_{2}, 0.02 \%$ Brij-35 and $0.2 \%$ sodium azide], and incubated overnight at $37^{\circ} \mathrm{C}$. The gels were stained with staining buffer $(0.5 \%$ Coomassie Brilliant Blue R-250 solution containing $10 \%$ acetic acid and $20 \%$ methanol) for $30 \mathrm{~min}$ and destained with $10 \%$ acetic acid solution. Areas of gelatinase activity were detected as clear bands against the blue-stained gelatin background, and relative band intensities were determined by the quantification of each band using the Gel Doc ${ }^{\mathrm{TM}} \mathrm{XR}+$ imaging system (Bio-Rad Laboratories). 

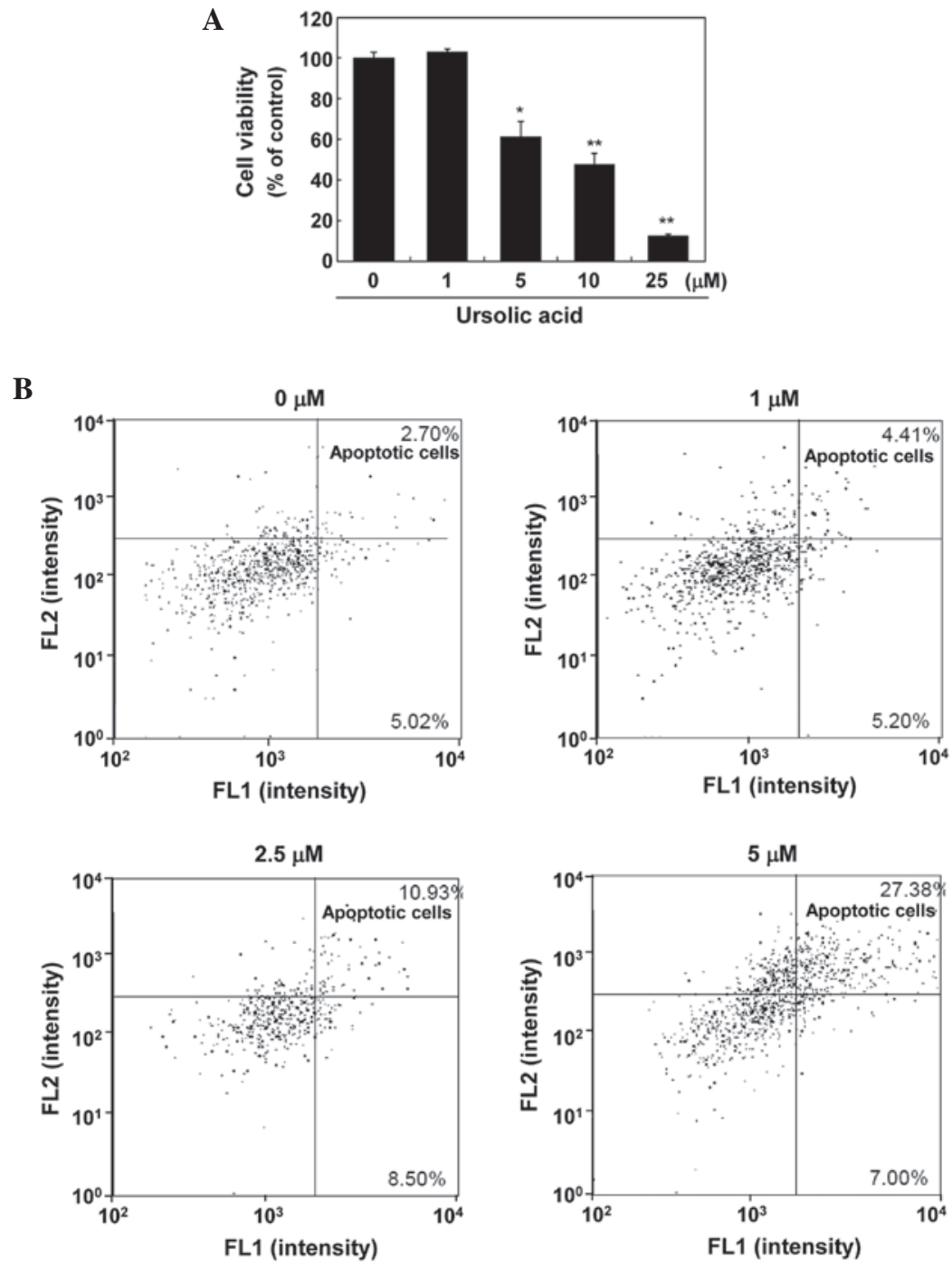

Figure 1. Ursolic acid inhibits the growth of SNU-484 cells. (A) The cells were treated with various concentrations of ursolic acid for $24 \mathrm{~h}$ and then subjected to an MTT assay. The results represent the mean \pm standard error of the mean for triplicates. ${ }^{*} \mathrm{P}<0.05$ and ${ }^{* *} \mathrm{P}<0.01$ vs. control. (B) The cells were treated with various concentrations of ursolic acid $(0,1.0,2.5$ and $5.0 \mu \mathrm{M})$ for $24 \mathrm{~h}$ and incubated with annexin V-fluorescein isothiocyanate (FITC) and propidium iodide (PI). The FITC and PI fluorescence was measured using a Vision CBA Image Cytometry system with FL-1 (530 nm) and FL-2 (585 nm) filters, respectively.

Statistical analysis. The results are presented as the mean \pm standard deviation of three independent experiments run in triplicate and analyzed by Student's t-test. $\mathrm{P}<0.05$ was considered to indicate a statistically significant difference.

\section{Results}

Ursolic acid inhibits cell growth in SNU-484 cells. To investigate the effect of ursolic acid on the growth of SNU-484 gastric cancer cells, an MTT assay was performed on cells treated with various concentrations of ursolic acid. As demonstrated in Fig. 1A, treatment of the SNU-484 cells with ursolic acid for $24 \mathrm{~h}$ inhibited growth in a dose-dependent manner $(\mathrm{P}<0.01)$, with a half maximal inhibitory concentration of $9 \mu \mathrm{M}$.

Ursolic acid induces apoptosis and regulates the expression of apoptosis-associated proteins. To investigate whether ursolic acid-induced growth inhibition involves apoptosis, a flow cytometric analysis was conducted. As demonstrated in Fig. 1B, ursolic acid induced the apoptosis of the SNU-484 cells in a concentration-dependent manner. Treatment of the SNU-484 cells with $5 \mu \mathrm{M}$ ursolic acid for $24 \mathrm{~h}$ resulted in a significant increase in annexin $\mathrm{V}$ - and propidium iodide -positive apoptotic cells $(27.38 \%)$ compared with the control cells $(2.70 \%)$. These results indicate that the observed growth inhibitory effect of ursolic acid may be due to the induction of apoptotic cell death.

To evaluate the molecular mechanisms underlying ursolic acid-induced apoptosis, the protein expression levels of PARP, pro-caspase-3, Bcl-2 and Bax were determined in cells treated with ursolic acid for $24 \mathrm{~h}$. PARP, a well-established substrate for caspase- 3 and thus an indicator of apoptosis (33), appeared to be cleaved by ursolic acid ( $\mathrm{P}<0.01$; Fig. $2 \mathrm{~A})$, and the expression of pro-caspase- 3 was decreased by ursolic acid $(\mathrm{P}<0.05$; Fig. 2B), indicating that ursolic acid may induce the activation of caspase-3 in the SNU-484 cells.

In addition, the expression levels of Bcl-2 and Bax were examined in the ursolic acid-treated cells. Ursolic acid dose-dependently inhibited the expression of $\mathrm{Bcl}-2$ $(\mathrm{P}<0.05)$, whereas Bax expression levels were increased by 
A
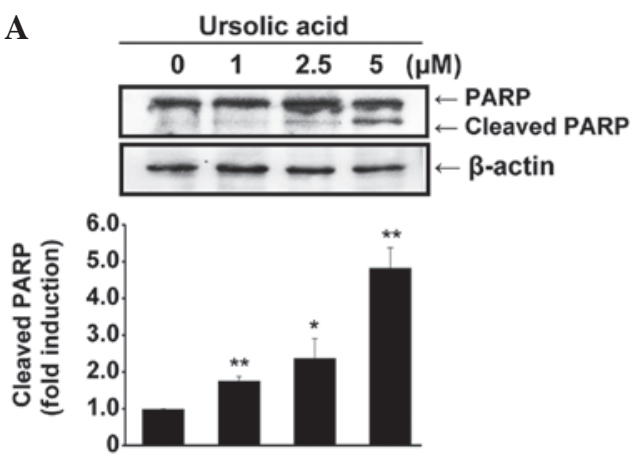

C
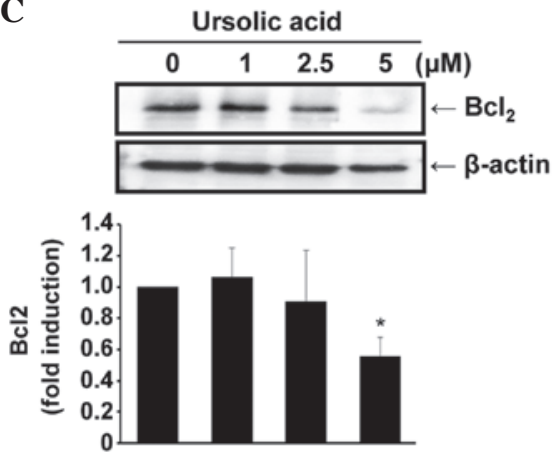

B

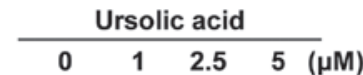

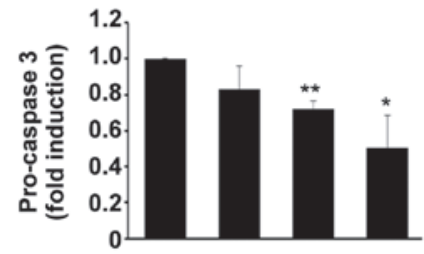

D
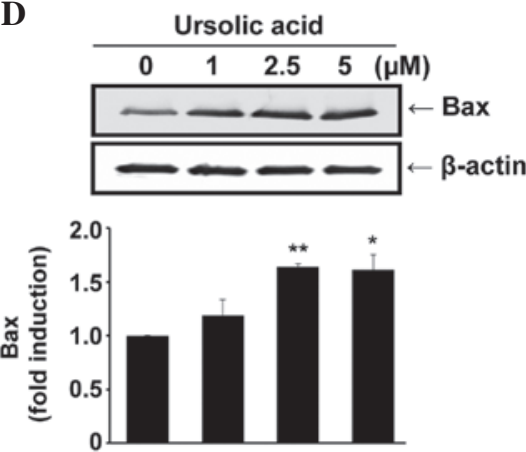

Figure 2. Ursolic acid regulates the expression of apoptosis-associated proteins in SNU-484 cells. Cells were treated with various concentrations of ursolic acid $(0,1.0,2.5$ and $5.0 \mu \mathrm{M})$ for $24 \mathrm{~h}$ and the protein expression levels of levels of (A) PARP, (B) pro-caspase 3, (C) Bcl-2 and (D) Bax were determined by performing an immunoblot analysis. ${ }^{*} \mathrm{P}<0.05$ and ${ }^{* *} \mathrm{P}<0.01$ vs. control. PARP, poly(ADP-ribose) polymerase; Bcl-2, B-cell lymphoma 2; Bax, Bcl-2-associated X protein.

A
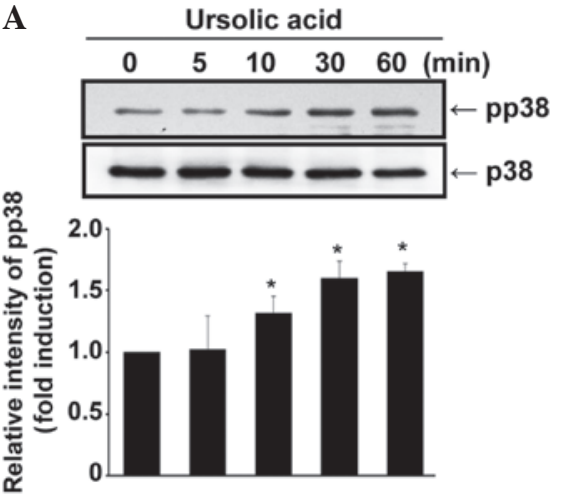

B
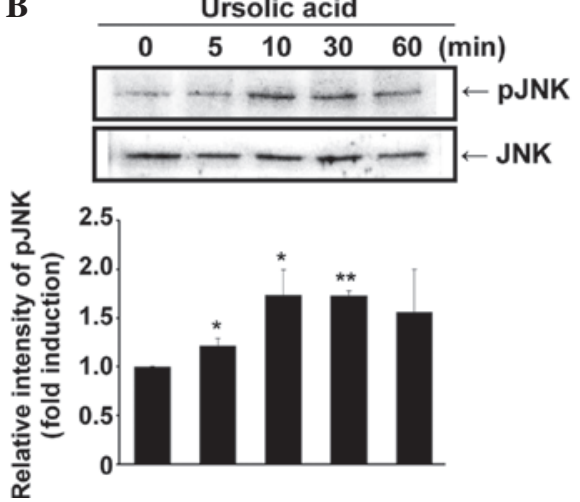

C
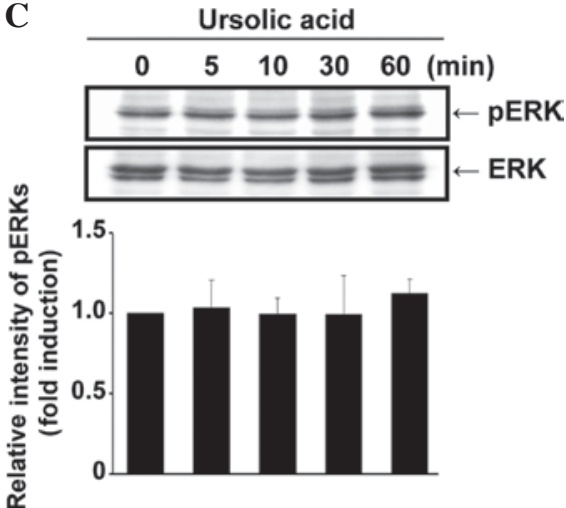

Figure 3. Ursolic acid activates p38 mitogen-activated protein kinase (MAPK) and JNK in SNU-484 cells. The cells were treated with $5 \mu$ M ursolic acid at the indicated time-points. The levels of phosphorylated and total (A) p38 MAPK, (B) JNK and (C) ERK were determined by performing immunoblot analysis. ${ }^{*} \mathrm{P}<0.05$ and ${ }^{* *} \mathrm{P}<0.01$ vs. control. JNK, c-Jun N-terminal kinase; $\mathrm{p}$, phosphorylated; ERK, extracellular signal-regulated kinase.

A

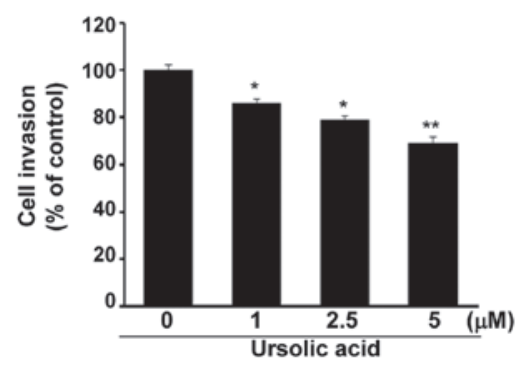

B
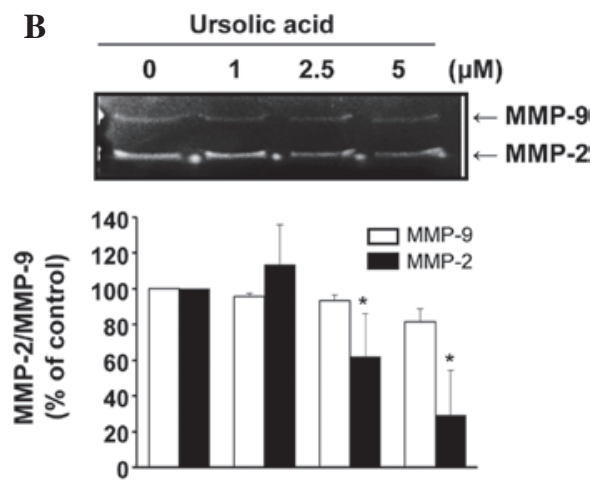

Figure 4. Ursolic acid inhibits invasion and MMP-2 expression in SNU-484 cells. (A) An in vitro invasion assay was conducted on SNU-484 cells treated with various concentrations of ursolic acid $(0,1.0,2.5$ and $5.0 \mu \mathrm{M})$ for $24 \mathrm{~h}$ and a (B) gelatin zymogram assay was conducted on conditioned media of SNU-484 cells treated with ursolic acid for $24 \mathrm{~h}$. ${ }^{*} \mathrm{P}<0.05$ and ${ }^{* *} \mathrm{P}<0.01$ vs. control. MMP, matrix metalloproteinase. 
the administration of ursolic acid $(\mathrm{P}<0.05$; Fig. $2 \mathrm{C}$ and $\mathrm{D})$. These data demonstrate that ursolic acid induces apoptosis in SNU-484 cells, possibly by downregulating the anti-apoptotic $\mathrm{Bcl}-2$ protein and upregulating the pro-apoptotic Bax protein.

Ursolic acid activates p38 MAPK and JNK. A kinetic study was performed to examine the effect of ursolic acid on the activation of MAPKs. As demonstrated in Fig. 3A, phospho-p38 MAPK expression was increased in the SNU-484 gastric cancer cells by the administration of ursolic acid in a time-dependent manner $(\mathrm{P}<0.05)$. In addition, the phosphorylation level of JNK increased up to $10 \mathrm{~min}$ after ursolic acid treatment $(\mathrm{P}<0.01)$ and then slightly decreased up to $60 \mathrm{~min}$ after (Fig. 3B). By contrast, the activation of ERK and phospho-ERK was not significantly altered by the administration of ursolic acid (Fig. 3C). These results demonstrate that ursolic acid activates p38 MAPK and JNK, indicating the possible involvement of these signaling pathways in the ursolic acid-induced apoptosis of SNU-484 gastric cancer cells.

Ursolic acid inhibits the invasive phenotype of SNU484 cells. To examine the effect of ursolic acid on the invasive phenotype of the SNU-484 cells, an in vitro invasion assay was performed. As demonstrated in Fig. 4A, the invasive ability of the SNU-484 cells was significantly inhibited by ursolic acid administration in a dose-dependent manner $(\mathrm{P}<0.01)$. In addition, the effect of ursolic acid on MMP-2 and/or MMP-9 in the SNU-484 cells was examined. As demonstrated in Fig. $4 \mathrm{~B}$, the expression level of MMP-2 was dose-dependently decreased by the administration of ursolic acid $(\mathrm{P}<0.05)$, while the expression of MMP-9 was not significantly reduced. These data indicate that ursolic acid may inhibit the invasiveness of SNU-484 cells via the downregulation of MMP-2.

\section{Discussion}

Gastric cancer is one of the predominant human malignancies, and chemoprevention using natural products has previously been considered as a promising approach for the control and management of cancer $(34,35)$. The present study demonstrated that ursolic acid efficiently induces apoptosis and inhibits the invasive phenotype of SNU-484 human gastric cancer cells. These findings indicate a potential application of ursolic acid in regulating the aggressiveness of human gastric cancer.

Cancer cells often escape apoptosis by increasing the expression levels of anti-apoptotic genes or by decreasing the expression of pro-apoptotic genes (22). Ursolic acid has previously been demonstrated to induce apoptosis by causing the release of cytosolic cytochrome $c$, activating caspase-3, reducing the expression of $\mathrm{Bcl}-2$ and increasing the expression of Bax in HeLa (36) and MDA-MB-231 breast cancer cells (37). Similarly, the results of the present study indicate that ursolic acid may induce apoptosis by decreasing the expression of $\mathrm{Bcl}-2$ and increasing the expression of Bax in SNU-484 gastric cancer cells.

The MAPK family of proteins regulate various stress responses, and thus are crucial for the maintenance of cells (38). Among the various MAPK pathways, the JNK and p38 MAPK pathways have been indicated to be key regulators of stress-induced apoptosis (39). There has previously been controversy regarding the role of p38 MAPK signaling in cell death; depending on the cell system used, p38 MAPK signaling has been shown to promote cell death $(40,41)$, and to enhance cell survival and growth $(42,43)$. Furthermore, ursolic acid has been demonstrated to induce apoptosis via the activation of JNK, but not p38 MAPK, in pituitary adenoma, human leukemia K562 and prostate cancer cells (42-46). The results of the present study demonstrated that ursolic acid activates JNK and p38 MAPK in human gastric cancer cells, indicating that the role of MAPK signaling in the induction of apoptosis may be cell-type specific.

Tumor cell invasion is an early step of the metastatic cascade, representing the onset of the transition from the benign stage to malignant progression (47). Numerous studies have identified an association between cell invasion and the inhibition of MMPs (48-50). Furthermore, our previous study and another study have demonstrated that among the MMPs, MMP-2 expression is associated with the invasive phenotype of gastric cancer cells $(51,52)$. Consistent with these previous studies, the present study demonstrated that ursolic acid inhibits the invasive phenotype of SNU-484 gastric cancer cells by downregulating MMP-2 expression.

In conclusion, the present study clearly demonstrates that ursolic acid induces apoptosis and inhibits cell invasion in SNU-484 human gastric cancer cells. Considering that gastric cancer is one of the most common types of cancer and that metastasis is the major cause of mortality in gastric cancer patients, the findings of the present study may provide insights into the potential application of ursolic acid as an agent for the prevention and treatment of human gastric cancer.

\section{Acknowledgements}

The present study was supported by the Duksung Women's University Research Grant 2012. The authors thank Dr Choon Sik Jeong of Duksung Women's University (Seoul, South Korea) for partaking in useful discussions on the study.

\section{References}

1. Bertuccio P, Chatenoud L, Levi F, Praud D, Ferlay J, Negri E, Malvezzi M and La Vecchia C: Recent patterns in gastric cancer: a global overview. Int J Cancer 125: 666-673, 2009.

2. Leung WK, Wu MS, Kakugawa Y, Kim JJ, Yeoh KG, Goh KL, Wu KC, Wu DC, Sollano J, Kachintorn U, et al; Asia Pacific Working Group of Gastric Cancer: Screening for gastric cancer in Asia: current evidence and practice. Lancet Oncol 9: 279-287, 2008

3. Crew KD and Neugut AI: Epidemiology of gastric cancer. World J Gastroenterol 12: 354-362, 2006.

4. Macdonald JS: Gastric cancer - new therapeutic options. N Engl J Med 355: 76-77, 2006.

5. Cunningham D and Chua YJ: East meets west in the treatment of gastric cancer. N Engl J Med 357: 1863-1865, 2007.

6. Ngo SN, Williams DB and Head RJ: Rosemary and cancer prevention: preclinical perspectives. Crit Rev Food Sci Nutr 51: 946-954, 2011.

7. Shishodia S, Majumdar S, Banerjee S and Aggarwal BB: Ursolic acid inhibits nuclear factor- $\kappa B$ activation induced by carcinogenic agents through suppression of $\mathrm{I} \kappa \mathrm{B} \alpha$ kinase and p65 phosphorylation: correlation with down-regulation of cyclooxygenase 2, matrix metalloproteinase 9, and cyclin D1. Cancer Res 63: 4375-4383, 2003.

8. Wang X, Zhang F, Yang L, Mei Y, Long H, Zhang X, Zhang J, Qimuge-Suyila and Su X: Ursolic acid inhibits proliferation and induces apoptosis of cancer cells in vitro and in vivo. J Biomed Biotechnol 2011: 419343, 2011. 
9. Lin CC, Huang CY, Mong MC, Chan CY and Yin MC: Antiangiogenic potential of three triterpenic acids in human liver cancer cells. J Agric Food Chem 59: 755-762, 2011.

10. Huang CY, Lin CY, Tsai CW and Yin MC: Inhibition of cell proliferation, invasion and migration by ursolic acid in human lung cancer cell lines. Toxicol In Vitro 25: 1274-1280, 2011.

11. Li Y, Xing D, Chen Q and Chen WR: Enhancement of chemotherapeutic agent-induced apoptosis by inhibition of $N F-\kappa B$ using ursolic acid. Int J Cancer 127: 462-473, 2010.

12. Ma CM, Cai SQ, Cui JR, Wang RQ, Tu PF, Hattori M, Hattori M and Daneshtalab M: The cytotoxic activity of ursolic acid derivatives. Eur J Med Chem 40: 582-589, 2005.

13. Shanmugam MK, Manu KA, Ong TH, Ramachandran L, Surana R, Bist P, Lim LH, Kumar AP, Hui KM and Sethi G: Inhibition of CXCR4/CXCL12 signaling axis by ursolic acid leads to suppression of metastasis in transgenic adenocarcinoma of mouse prostate model. Int J Cancer 129: 1552-1563, 2011.

14. De Angel RE, Smith SM, Glickman RD, Perkins SN and Hursting SD: Antitumor effects of ursolic acid in a mouse model of postmenopausal breast cancer. Nutr Cancer 62: 1074-1086, 2010.

15. Prasad S, Yadav VR, Sung B, Reuter S, Kannappan R, Deorukhkar A, Diagaradjane P, Wei C, Baladandayuthapani V, Krishnan S, et al: Ursolic acid inhibits growth and metastasis of human colorectal cancer in an orthotopic nude mouse model by targeting multiple cell signaling pathways: chemosensitization with capecitabine. Clin Cancer Res 18: 4942-4953, 2012.

16. Yeh CT, Wu CH and Yen GC: Ursolic acid, a naturally occurring triterpenoid, suppresses migration and invasion of human breast cancer cells by modulating c-Jun N-terminal kinase, Akt and mammalian target of rapamycin signaling. Mol Nutr Food Res 54: 1285-1295, 2010.

17. Yu LB, Wang J, Ma BZ and Sun WZ: Inhibitive effect of ursolic acid on the invasion and metastasis of ovarian carcinoma cells HO-8910PM. Sichuan Da Xue Xue Bao Yi Xue Ban 41: 986-988, 2010 (In Chinese).

18. Hanahan D and Weinberg RA: Hallmarks of cancer: the next generation. Cell 144: 646-674, 2011.

19. Steller-Stevenson WG: Type IV collagenases in tumor invasion and metastasis. Cancer Metastasis Rev 9: 289-303, 1990.

20. Stetler-Stevenson WG, Liotta LA and Kleiner DE Jr: Extracellular matrix 6: role of matrix metalloproteinases in tumor invasion and metastasis. FASEB J 7: 1434-1441, 1993.

21. Chiarugi V, Magnelli L, Cinelli M and Basi G: Apoptosis and the cell cycle. Cell Mol Biol Res 40: 603-612, 1994.

22. Fernald $\mathrm{K}$ and Kurokawa M: Evading apoptosis in cancer. Trends Cell Biol 23: 620-633, 2013.

23. Kroemer G: The proto-oncogene Bcl-2 and its role in regulating apoptosis. Nat Med 3: 614-620, 1997.

24. Ashkenazi A and Dixit VM: Death receptors: signaling and modulation. Science 281: 1305-1308, 1998.

25. Blanc C, Deveraux QL, Krajewski S, Jänicke RU, Porter AG, Reed JC, Jaggi R and Marti A: Caspase-3 is essential for procaspase-9 processing and cisplatin-induced apoptosis of MCF-7 breast cancer cells. Cancer Res 60: 4386-4390, 2000.

26. Seger R and Krebs EG: The MAPK signaling cascade. FASEB J 9: 726-735, 1995.

27. Westwick JK, Bielawska AE, Dbaibo G, Hannun YA and Brenner DA: Ceramide activates the stress-activated protein kinases. J Biol Chem 270: 22689-22692, 1995.

28. Tibbles LA and Woodgett JR: The stress-activated protein kinase pathways. Cell Mol Life Sci 55: 1230-1254, 1999.

29. Davis RJ: Signal transduction by the JNK group of MAP kinases. Cell 103: 239-252, 2000.

30. Yu R, Shtil AA, Tan TH, Roninson IB and Kong AN: Adriamycin activates c-jun $\mathrm{N}$-terminal kinase in human leukemia cells: a relevance to apoptosis. Cancer Lett 107: 73-81, 1996.

31. Chen YR, Meyer CF and Tan TH: Persistent activation of c-Jun N-terminal kinase 1 (JNK1) in gamma radiation-induced apoptosis. J Biol Chem 271: 631-634, 1996.

32. Cagnol S and Chambard JC: ERK and cell death: mechanisms of ERK-induced cell death - apoptosis, autophagy and senescence. FEBS J 277: 2-21, 2010.

33. Germain M, Affar EB, D'Amours D, Dixit VM, Salvesen GS and Poirier GG: Cleavage of automodified poly(ADP-ribose) polymerase during apoptosis. Evidence for involvement of caspase-7. J Biol Chem 274: 28379-28384, 1999.
34. Karikas GA: Anticancer and chemopreventing natural products: some biochemical and therapeutic aspects. J BUON 15: 627-638, 2010.

35. Ou Y, Li Q, Wang J, Li K and Zhou S: Antitumor and apoptosis induction effects of paeonol on mice bearing EMT6 breast carcinoma. Biomol Ther (Seoul) 22: 341-346, 2014.

36. Li Y, Lu X, Qi H, Li X, Xiao X and Gao J: Ursolic acid induces apoptosis through mitochondrial intrinsic pathway and suppression of ERK1/2 MAPK in HeLa cells. J Pharmacol Sci 125: 202-210, 2014.

37. Kim KH, Seo HS, Choi HS, Choi I, Shin YC and Ko SG: Induction of apoptotic cell death by ursolic acid through mitochondrial death pathway and extrinsic death receptor pathway in MDA-MB-231 cells. Arch Pharm Res 34: 1363-1372, 2011.

38. Wada T and Penninger JM: Mitogen-activated protein kinases in apoptosis regulation. Oncogene 23: 2838-2849, 2004.

39. Raingeaud J, Gupta S, Rogers JS, Dickens M, Han J, Ulevitch RJ and Davis RJ: Pro-inflammatory cytokines and environmental stress cause p38 mitogen-activated protein kinase activation by dual phosphorylation on tyrosine and threonine. J Biol Chem 270: 7420-7426, 1995.

40. Sarkar D, Su ZZ, Lebedeva IV, Sauane M, Gopalkrishnan RV, Valerie K, Dent P and Fisher PB: Mda-7 (IL-24) mediates selective apoptosis in human melanoma cells by inducing the coordinated overexpression of the GADD family of genes by means of p38 MAPK. Proc Natl Acad Sci USA 99: 10054-10059, 2002.

41. Porras A, Zuluaga S, Black E, Valladares A, Alvarez AM, Ambrosino C,Benito M and Nebreda AR:P38 $\alpha$ mitogen-activated protein kinase sensitizes cells to apoptosis induced by different stimuli. Mol Biol Cell 15: 922-933, 2004.

42. Yosimichi G, Nakanishi $T$, Nishida $T$, Hattori $T$, Takano-Yamamoto T and Takigawa M: CTGF/Hcs24 induces chondrocyte differentiation through a p38 mitogen-activated protein kinase (p38MAPK), and proliferation through a $\mathrm{p} 44 / 42$ MAPK/extracellular-signal regulated kinase (ERK). Eur J Biochem 268: 6058-6065, 2001.

43. Park JM, Greten FR, Li ZW and Karin M: Macrophage apoptosis by anthrax lethal factor through p38 MAP kinase inhibition. Science 297: 2048-2051, 2002.

44. Gong YY, Liu YY, Yu S, Zhu XN, Cao XP and Xiao HP: Ursolic acid suppresses growth and adrenocorticotrophic hormone secretion in AtT20 cells as a potential agent targeting adrenocorticotrophic hormone-producing pituitary adenoma. Mol Med Rep 9: 2533-2539, 2014.

45. Liu XS and Jiang J: Induction of apoptosis and regulation of the MAPK pathway by ursolic acid in human leukemia K562 cells. Planta Med 73: 1192-1194, 2007.

46. Zhang YX, Kong CZ, Wang HQ, Wang LH, Xu CL and Sun YH: Phosphorylation of Bcl-2 and activation of caspase-3 via the c-Jun N-terminal kinase pathway in ursolic acid-induced DU145 cells apoptosis. Biochimie 91: 1173-1179, 2009.

47. Lynch CC and Matrisian LM: Matrix metalloproteinases in tumor-host cell communication. Differentiation 70: 561-573, 2002.

48. Liotta LA, Tryggvason K, Garbisa S, Hart I, Foltz CM and Shafie S: Metastatic potential correlates with enzymatic degradation of basement-membrane collagen. Nature 284: 67-68, 1980.

49. Lee YD, Cui MN, Yoon HH, Kim HY, Oh IH and Lee JH: Down-modulation of Bis reduces the invasive ability of glioma cells induced by TPA, through NF- $\mathrm{B}$ mediated activation of MMP-9. BMB Rep 47: 262-267, 2014.

50. Ham M and Moon A: Inflammatory and microenvironmental factors involved in breast cancer progression. Arch Pharm Res 36: 1419-1431, 2013.

51. Yong HY and Moon A: Roles of calcium-binding proteins, S100A8 and S100A9, in invasive phenotype of human gastric cancer cells. Arch Pharm Res 30: 75-81, 2007.

52. Tsuchiya A, Kikuchi Y, Ando Y, Yoshida T and Abe R: Lymph node metastases in gastric cancer invading the submucosal layer. Eur J Surg Oncol 21: 248-250, 1995. 